\title{
Synthesis and Crystalline Structure of Palladium(II) Mononuclear Trifluoroacetate Complex
}

\author{
A. V. Eremin ${ }^{a, b}$, D. D. Vaulina ${ }^{a}$, M. A. Stepanova ${ }^{a}$, and A. N. Belyaev ${ }^{a}$ \\ ${ }^{a}$ St. Petersburg State Institute of Technology, Moskovskii pr. 26, St. Petersburg, 190013 Russia \\ e-mail:ha9room@gmail.com \\ ${ }^{b}$ Almazov Federal Center of Heart, Blood, and Endocrinology, St. Petersburg, Russia
}

Received July 15, 2010

DOI: $10.1134 / \mathrm{S} 1070363211020253$

Palladium acetate [1] is one of compounds, which found wide application both in laboratory practice and in industry. It is actively used as a precursor in syntheses of other palladium complexes [2]. On heating or irradiation the palladium acetate is readily reduced to form thin films or colloids and nanoparticles [3].

Complexes $(\mathrm{N} \cap \mathrm{N}) \mathrm{PdL}_{2} \quad[\mathrm{~N} \cap \mathrm{N}$ is a bidentate nitrogen-containing aromatic ligand: 1,10-phenanthroline (phen), 2,2'-dipyridyl, or their derivatives] are capable to form compounds with dioxygen or binuclear oxo(hydroxo) species active in the aerobic oxidation reactions of organic substrates [4].

In this work we present the synthesis and the X-ray crystal analysis (XCA) data of a new palladium(II) mononuclear trifluoroacetate complex $[\mathrm{Pd}(\mathrm{phen})$. $\left.\left(\mathrm{CF}_{3} \mathrm{COO}\right)_{2}\right]$ (I). Complex I crystallizes in the monoclinic system with $P-1$ space group; $a$ 8.4941(9), b 19.312(2), c 12.9728(10) A, $\beta 127.46(0)^{\circ}, \quad V$ 1689.14(648) $\AA^{3}, Z 4$, and $R 3.85 \%$. The crystal structure of complex I involves stack interactions both between palladium atoms ( $\mathrm{Pd} \cdots \mathrm{Pd} 3.322 \AA$ ) and phenanthroline ligands $(\pi-\pi$ interactions, average interplanar distance of $3.42 \AA$ ) of neighboring molecules.

The basic fragment of the complex I structure is a distorted square-planar fragment formed by nitrogen atoms of 1,10-phenanthroline and oxygen atoms of trifluoroacetate coordinated monodentately to the central palladium atom (angles: $\mathrm{N}^{1} \mathrm{PdO}^{1} 96.79, \mathrm{~N}^{1} \mathrm{PdN}^{2}$ 82.25, $\mathrm{N}^{2} \mathrm{PdO}^{4}$ 92.36, and $\mathrm{O}^{1} \mathrm{PdO}^{4} 88.45^{\circ}$ ).

Bis(O-trifluoroacetate)1,10-phenanthrolinepalladium(II). To $150 \mathrm{mg}(0.419 \mathrm{mmol})$ of $\mathrm{Pd}(\mathrm{phen}) \mathrm{Cl}_{2}$, obtained by the modified procedure [5] and suspended in $20 \mathrm{ml}$ of acetonitrile, $185.3 \mathrm{mg}(0.839 \mathrm{mmol})$ of $\mathrm{CF}_{3} \mathrm{COOAg}$ dissolved in a minimal amount of acetonitrile was added. After filtering-off the precipitated $\mathrm{AgCl}$, the reaction mixture was evaporated in air at room temperature. Yellow needle-like crystals precipitated from the solution in some days. Yield $\sim 30 \%$ (counting on $\mathrm{Pd}$ ). The complex is readily soluble in alcohol and acetonitrile. IR spectrum $(\mathrm{KBr})$, $\mathrm{cm}^{-1}: 1679 ; 1516 ; 1430 ; 1403 ; 1209 ; 1132 ; 843 ; 806$; 725; 716. Found, \%: C 37.8; H 1.72; Pd 21.00; N 5.14. $\mathrm{C}_{16} \mathrm{H}_{8} \mathrm{~F}_{6} \mathrm{~N}_{2} \mathrm{O}_{4} \mathrm{Pd}$. Calculated, \%: C 37.49; H 1.57; Pd 20.76; N 5.46 .

Crystallographic data for complex I are deposited in the Cambridge bank of structural data (CCDC 773035).

\section{REFERENCES}

1. Mulagaleev, R.F., Kirik, S.D., and Golovnev, N.N., $Z h$. Sibirskogo Gos. Univ., 2008, no. 1, p. 249.

2. Bakhmutov, V.I., Ferry, J.F., Cotton, A.F., Ibragimov, S., and Murillo, C.A., Dalton Trans., 2005, vol. 11, p. 1989.

3. Cheng, C.D., Gonela, R.K., Gu, Q., and Haynie, D.T., Nano Lett., 2005, vol. 5, p. 175.

4. Comprehensive Coordination Chemistry II, McCleverty, J.A. and Meyer, T.J., Eds., 2005, vol. 6, p. 570. 